\title{
TRANSMEDIA STORYTELLING EDUTAINMENT EXPERIENCE IN ENGINEERING STUDIES
}

\author{
Elena del Val, Antonio González \\ Departamento de Informática e Ingeniería de Sistemas, Universidad de Zaragoza, Escuela \\ Universitaria Politécnica de Teruel (SPAIN)
}

\begin{abstract}
Transmedia Storytelling Edutainment is a new learning paradigm that develops from the coordinated and strategic use of multiple media/platforms for the communication of a story (content), involving students in the story as prosumers (producers+consumers). Experiential learning combined with storybased curriculums can be a very effective means of educating students. Specifically, Transmedia Storytelling Edutainment is effective in improving engagement, motivation and knowledge retention with students. Experiences have been made with young people in basic education, but they are scarce in university studies and more specifically in technical bachelor's degrees. Transmedia storytelling is a complex task that requires design considerations of narrative, engagement, and interaction. This paper analyses the structure and characteristics of transmedia experiences in university. Based on the results of the analysis, we propose a transmedia experience in a technical subject of the Degree in Computer Science. This strategy takes into account the following aspects: the story should be convincing and based on realism; the promotion of cooperation and a sense of community be promoted; and that there be multimodality in the learning environments, as well as challenging students to go deeper into the course material.
\end{abstract}

Keywords: Participatory culture, storytelling, collaboration, interaction, learning, university.

\section{INTRODUCTION}

The traditional teaching-learning methods used in schools, colleges and universities have been challenged with the emergence of new technologies and the ubiquity of information that allows new opportunities to work with active methodologies [4]. As a result, educators have begun to explore different learning methods to meet the needs of the "new student", incorporating new inputs, media consumption and production practices, global resources, and accommodating the shift towards an environment centered more on the student [5]. This is the case of the use of methodologies based on transmedia.

The term transmedia emerged in 1991 in Marsah Kinder's book [1]. However, the most commonly used definition is the one proposed by Jenkins [2], where the term transmedia history is defined as a story that unfolds on multiple platforms, and where each contribution on these platforms provides a relevant contribution to the global story. Other authors [2] have defined the term transmedia as a continuous process of co-creation between producers and audiences to complete a story. This idea of co-creation or co-production of content has also been highlighted by Munaro [4], who considers that transmedia narrative unfolds on various platforms where each contribution is relevant and where a new type of relationship emerges between receivers and platforms that involves their participation and interrelation.

The use of transmedia has been carried out mainly in the area of communication. However, in recent years, it is being adopted as a new teaching method while maintaining its original meaning $[4,6,7,8]$. In the context of education, Raybourn [5] defines transmedia storytelling as a system that represents the core of an experience that unfolds through different media platforms involving students in their learning process. The contributions made by students in each medium should reinforce improvements in their performance, reflection and behavior. The use of social media today and its inclusion as a platform in a transmedia strategy can facilitate teaching in different ways that enrich the core experience.

Other definitions are more specific about the means to be used in a transmedia strategy. For example, Ambrosino [6] considers transmedia narratives in education to those stories that are developed through multiple media platforms: e-learning, virtual campuses, social networks, open educational resources and the contexts of presence. These narratives affect the pedagogical experience. A similar point of view is presented by Rodrigues and Bidarra [9]. They propose the use of transmedia projects where worlds are created through stories that can be used to meet educational objectives by reinforcing and supporting content aimed at students. 
Other authors such as Lima [10] emphasize the use of transmedia as a new way of presenting academic content in a way that appeals to students, challenging the notion that education and entertainment are opposite ends of a spectrum. In addition, the use of transmedia in education also makes it possible to connect educational content with activities that are present in students' daily lives [11].

The use of transmedia can be applied to support traditional learning in several ways: (i) as examples of concepts taught in a traditional way; (ii) as case studies to be resolved by the students; and (iii) as advice to help students solve problems [12]. In general, the use of transmedia in education has numerous advantages [9]. It allows the development of strategies that are best adapted to the context of each student, taking into account the students' different learning stages, unique characteristics, and interests. In addition, it allows learning to take place in a more natural environment as a result of an interactive communication process. Learning carried out within the context of a story also makes the student more predisposed to learn since he or she is familiar with some details and at the same time is learning new concepts.

Therefore, it could be said that the use of transmedia that combines stories, communication, and new technologies can be considered a meeting point for teachers and students in the teaching-learning process [7]. Thus, some transmedia projects and experiences have already been carried out in the educational context although many of them have an exploratory and experimental character. For instance, Martínez [7] describes the work done with university students. In this work, the students had to analyze the design, creation and dissemination of transmedia content and analyze the role these could play in establishing participatory cultures and social and community development. In addition, they also identified the possibilities of transmedia projects at the university for the development of soft skills, the management of tacit knowledge and the collective construction of knowledge.

However, carrying out a transmedia project is not an easy task due to the skills required. Grandío-Pérez [13] carries out a study of how the skills of transmedia are being trained in the Spanish University environment. The analysis of the results of the study concludes that there is a slow incorporation of transmedia skills in the Spanish educational environment and that it would be convenient to incorporate issues such as multimodal reception or collaborative creation processes. Ambrosino [6] also carries out a study of transmedia narratives in the context of higher education and reaches a similar conclusion to Grandío-Perez [13]. According to Ambrosino [6], transmedia narrative should occupy a prominent place in the processes of didactic configuration.

\section{DEVELOPING A TRANSMEDIA PROJECT}

Due to the use of transmedia in social and educational contexts is relatively recent and involves many digital media elements, conducting a transmedia project can create a lot of confusion about what to consider when creating a transmedia story and how to conduct a transmedia project. In this section, we analyze different approaches to transmedia project design and the main components of transmedia narratives.

Hazboun [3] presents a set of stages to create a transmedia project. These stages range from the most general, where there is a global vision of the project and the story, to the most specific where the platforms and the interactions between them are detailed. The stages considered can be summarized in: storyworld, transmedia, and story platform or technical phase. In the storyworld stage the goal is to find a story idea and establish a story path to let the audience learn about the story, its characters and world. Next stage is transmedia. At this stage, the different media chosen and the content to work on are established as well as the relationships that will be established between them. Finally, at the technical phase, the different technical possibilities are analyzed and the content selected is deployed in them. Similarly, Gosciola [14] considers that the development of a transmedia project is carried out through the following steps. First, an internal narrative is made, defining the characters and working multiple plot lines (displaying the life of each character). Then, the plots are distributed on different media platforms. Finally, the plot lines and media platforms come together in an attempt to unify the work and establish coherence.

Sánchez [15], when designing a transmedia project, places more emphasis on building a world than a story. Subsequently, the platforms, where the different stories will be displayed and whose objectives will be to motivate the participation considering the user experience, are taken into account.

When developing story, there are different strategies that can be useful [16]. Scolari proposes four strategies. The first is the creation of micro stories that enrich the fictional world (comics, online videos, video games) and are located in between the main story. The second is the creation of simultaneous 
stories to the main story. The third is the creation of "satellite" stories that may be distant from the main story. Finally, the last strategy is the creation of user-generated content platforms (eg. blogs).

For Nooijer [17] the development of transmedia narration implies three design considerations: narrative (i.e., defining the elements such as characters, institutions, locations involved in the world-building), commitment (i.e., determining the elements that promote commitment and participation at the mental and emotional level) and interaction (i.e., describing how users interact and navigate through the transmedia narrative). Nooijer also proposes a road map for implementing transmedia educational projects. This road map consists on the following steps: identifying target audience and personas, designing a storyworld, designing a story, selecting the proper media/modes, aggregating content, and extending the narrative across multiple media.

An interesting approach to design a transmedia project is the adaptation of the Business Model Canvas (BMC) as designed and described by Osterwalder and Pigneur [18]. This idea was used by CENTRO [19] to create a Transmedia Storytelling Canvas for Education. The Transmedia Storytelling for Education Canvas created by CENTRO is built in layers ranging from the most general or abstract ideas to the most specific of a transmedia project (see Figure 1). The outermost layer is the most abstract and describes the objective of the project and the learning objectives associated with it. The second layer describes the characters that could participate in the story. Then, in the third layer, the story and the stage are defined. Within the story layer, several elements are defined. On the one hand, the media through which the story is supported, the relationships between these media and the depth of the story in each one. On the other hand, the canvas includes narrative considerations such as emotional bonds and emotional states that should evoke, the configuration, confrontation and resolution. Finally, the results of the operational level are discussed; what experiences the student should have; and, the assessment process. The student's level of achievement should be measured according to the activities that the students have undertaken.

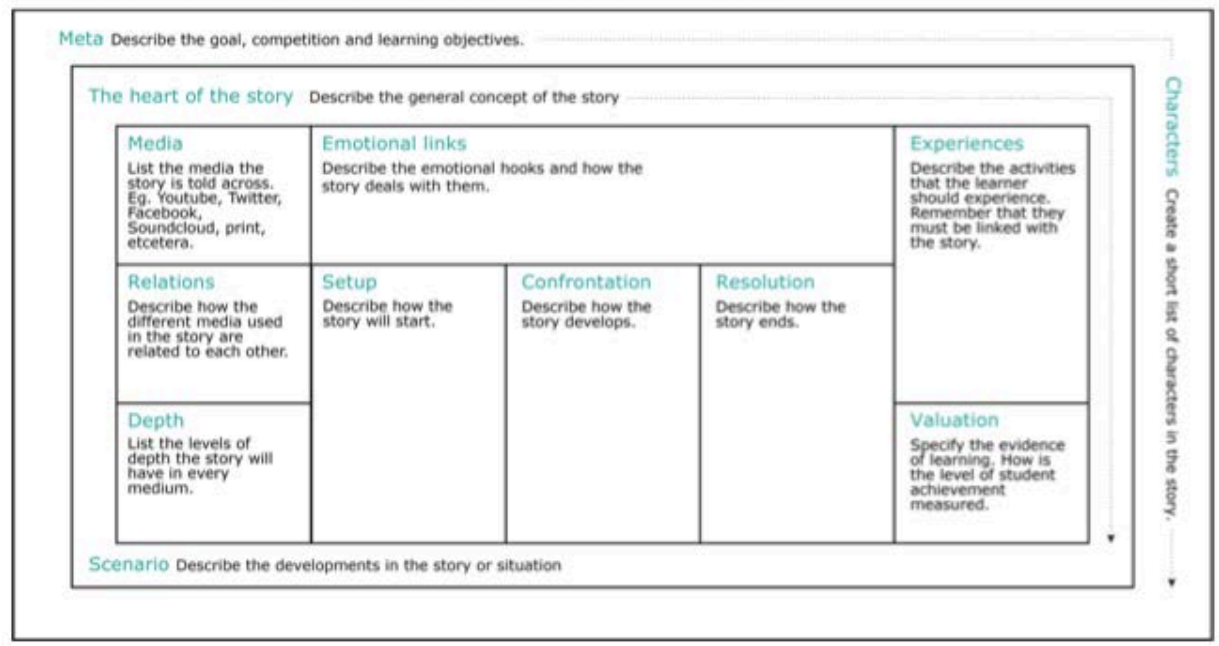

Figure 1. Transmedia Storytelling Canvas for Education [17].

A similar proposal for the construction of a transmedia project was proposed by Gambarato [20]. The model consists of ten dimensions that must be taken into account when developing a transmedia project: objective, narrative, construction of the world, characters, extensions, media and gender platforms, audience and market, participation, structure and aesthetics.

\section{TRANSMEDIA PROJECT PROPOSAL}

The transmedia project proposal presented is in the context of the first year of the Degree in Computer Science at Universidad de Zaragoza. The subject in which the transmedia experience takes place is Programming II, a core subject of the second semester that has 6 ECTS credits. The number of students involved is 30. To describe the project proposal, we have followed the Transmedia Storytelling for Education Canvas. In the following paragraphs, we describe the different elements of the canvas applied to the context of the Programming II subject. 
Meta. The goal of the project is to conceive, design and develop engineering projects. The learning objectives associated to the project are: (i) to develop robust programs of medium size in a modular way, providing them with robustness; (ii) formally specifying algorithms; (iii) designing correct recursive and iterative algorithms; (iv) analyze the cost of iterative and recursive algorithms.

The heart of the story. The main story of the project will be focused on the context of an IT consulting company where several IT projects are developed. The main actors in this story will be several project managers and developers.

Media. The transmedia strategy will distribute the main elements of the agenda through multiple physical (e.g., classroom) and virtual (e.g., blog, Kahoot, and Moodle) channels to create a unified and coordinated student knowledge experience [21]. In addition, the students were consumers and creators of the subject content, thus becoming involved in the teaching-learning process.

The main channels used for the transmedia project were face-to-face classes, the Moodle platform, a blog, and the Kahoot tool. Below, we describe in more detail the role that each media plays:

- Face-to-face classes: the classes will be technical training seminars for the acquisition of the most relevant knowledge in the execution of the projects carried out by the company.

- Moodle platform: it is a tool provided by the University that was mainly used for: (i) facilitating access to the subject material (documentation of the teaching units in .pdf format); (ii) communicating relevant milestones within the subject to students; and (iii) managing grades.

- Web site: this channel will be used to provide the information about the projects that the students should work on during the practical lessons. This web site represents the site of the IT consulting company. This web site will also contain a blog.

- Blog (publication of text and video content): this channel will be initially used by the teacher to upload videos, files, and latest news on different aspects related to programming or the development of IT projects. Students are encouraged to contribute adding comments to existing posts, uploading news, or creating new content. The blog will be created using Google's Blogger platform.

- Kahoot: it is a free platform that allows the creation of questionnaires through gamification. These questionnaires are known as kahoots. The tool was used in two ways. On the one hand, kahoots will be carried out in the classroom, which served to reinforce the theoretical concepts seen in the didactic units, and to review the contents in the face-to-face classes before the evaluation acts. The students answered in a determined time making use of their electronic devices, obtaining points for each correct answer. At the end, a ranking was generated with the scores of the participants. On the other hand, the teacher offered the possibility of the students themselves voluntarily sending their questions to make new kahoots. The objective of this modality is that the students would deepen their theoretical knowledge in order to publish their questions. It should be noted that kahoots can be done individually or as a group.

Relations. The main relations between the different media involved in the project are described in Figure 2.

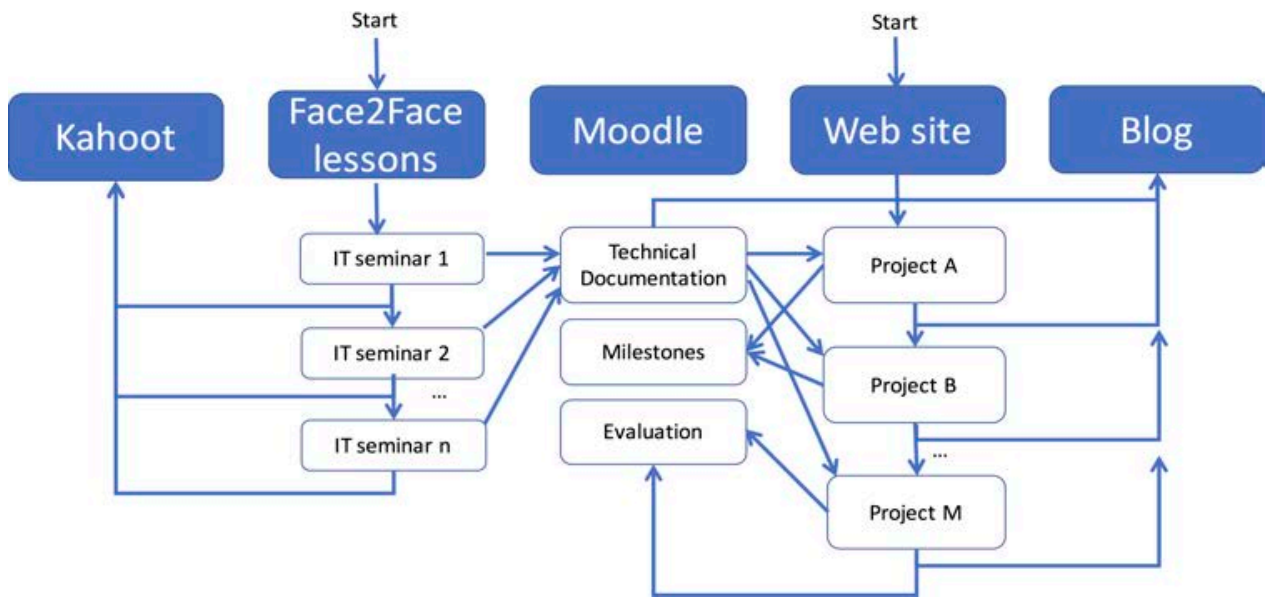

Figure 2. Relations between the different media. 
Depth. We have considered three levels of depth ranging from 3 (maximum depth) to 1 (minimum depth). The media with level 3 of depth will be the Face-to-face lessons, where the most important concepts will be worked on in depth, and the web site, where the projects the students will work on will be described. Moodle and Kahoot will have a level 2 of depth. The most important technical documentation will be uploaded in Moodle and will serve as support for the implementation of the projects. In Kahoot, questionnaires will be left with the most relevant ideas that should be clear as the course progresses. Finally, the Blog will have a level of depth of 1 . The blog will work on more general aspects such as news related to computer projects or problems that may have arisen for students during the performance of the projects and possible solutions that other students provide.

Emotional links. Students will be able to work on the subject from a context closer to professional experience such as working on projects within the context of an IT consulting company. This will help to increase motivation and get them more involved during the development of the work.

Setup. The story that is proposed as a thread is the performance of a series of projects to a computer consulting company in which they work as developers. The person in charge of each project (in this case the teacher) will assign them the different projects.

Confrontation. Each project will require the acquisition of essential technical knowledge that will be worked on in seminars and through self-evaluation questionnaires. Once this knowledge has been acquired, the students will be able to start working on the assigned project. Each project assigned to them has a description (more or less detailed) of what the project consists of and what it is expected to achieve. They will have to do the design and implementation of the project. All the information about the project can be found on the company's website. If along the development of the project problems arise or students find interesting information related to the project, they will be able to upload it to the blog and comment it with the rest of their classmates.

Resolution. Each project will have an associated delivery date. The documentation and the code developed must be uploaded to the Moodle platform for later review and evaluation by the project leader (the teacher).

Experiences. With this transmedia experience students, will have to carry out the design and implementation of several projects associated with the computer consulting company where the degree of difficulty increases as the course progresses. The student should: (i) take into account what knowledge of those worked on in the seminars is necessary to apply; (ii) coordinate and work with a project partner and resolve or consult doubts with the project manager (teacher); (iii) organize temporarily to be able to reach the delivery date of the project and that it has the necessary quality to pass the evaluation.

Valuation. The evaluation will be carried out by means of the delivery of the different projects and a practical test where the student should carry out the implementation of some part of a project that is incomplete.

\section{CONCLUSIONS}

The use of transmedia in education has provided a wide offer of channels that students currently use (i.e., web sites, e-learning platforms, blogs, social networks) to provide subject contents through the development a story that acts as the core. These media can be integrated within face-to-face classes and traditional methodologies. Furthermore, the use of transmedia makes it possible to take learning beyond the classroom through the consumption and creation of content where students had to discovery, research, and generate new content to apply concepts learned in class to everyday life situations.

In this article, we have analyzed different approaches that focus on the development of transmedia projects and especially those applied to the context of education. Once the different phases of a transmedia project have been analyzed, we have developed a proposal for the Programming II subject of the Degree in Computer Engineering following the proposal of Transmedia Storytelling for Education Canvas. We have detailed the core story, the media involved and their relationships, narrative considerations such as emotional bonds and emotional states that should emerge, the setup of the story, its development, and resolution as well as the experiences the student should have and the assessment process. 


\section{ACKNOWLEDGEMENTS}

This work is supported by the Universidad de Zaragoza project PIIDUZ_19_348 Aplicación De Narrativas Transmedia En El Contexto De Asignaturas De Informática E Ingeniería De Sistemas.

\section{REFERENCES}

[1] Kinder, M. (1991). Playing with power in movies, television, and video games: from Muppet Babies to Teenage Mutant Ninja Turtles. Univ of California Press.

[2] Jenkins, H. (2003, January 15). Transmedia storytelling. Moving characters from books to films to video games can make them stronger and more compelling. Technology Review.

[3] Hazboun, S. (2014). Challenges of Transmedia Storytelling: Considerations of Creating of Transmedia Projects. Sweden: Dalarna University, pp.1-57.

[4] Munaro, A. C., \& Vieira, A. M. D. P. (2016). Use of Transmedia Storytelling for Teaching Teenagers. Creative Education, 7(07), 1007.

[5] Raybourn, E. M. (2014). A new paradigm for serious games: Transmedia learning for more effective training and education. Journal of computational science, 5(3), 471-481.

[6] Ambrosino, M. A. (2017). Docencia y narrativas transmedia en la educación superior. Trayectorias Universitarias, 3.

[7] Martínez, R. A., De la Iglesia Atienza, L., \& Zamora, E. G. (2018). Creación de contenidos transmedia en la sociedad hiperconectada. Una etnografía digital con jóvenes universitarios. Revista Fuentes, 20(1), 29-41.

[8] Scolari, C. A. (2019). Transmedia Education. From the contents generated by the users to the contents generated by the students.

[9] Rodrigues, P., \& Bidarra, J. (2014). Transmedia storytelling and the creation of a converging space of educational practices. International Journal of Emerging Technologies in Learning(iJET), 9, 42-48.

[10] Lima, E. F. O. (2014). Recursos Educacionais Abertos: Ensino através de Conteúdos Transmidiáticos. Anais do XVI Congresso de Ciências da Comunicação na Região Nordeste, João Pessoa, 15-17 May 2014, 1-11.

[11] Sharda, N. (2010). Using Storytelling as the Pedagogical Model for Web-Based Learning in Communities of Practice. In N. Karacapilidis (Ed.), Web-Based Learning Solutions for Communities of Practice: Developing Virtual Environments for Social and Pedagogical Advancement (pp. 67-82).

[12] Jonassen, D. H., \& Hernandez-Serrano, J. (2002). Case-based reasoning and instructional design: Using stories to support problem solving. Educational Technology Research and Development, 50(2), 65-77.

[13] del Mar Grandío-Pérez, M. (2016). El transmedia en la enseñanza universitaria. Análisis de las asignaturas de educación mediática en España (2012-2013). Palabra clave, 19(1), 85-104.

[14] Gosciola, V. (2011). Narrativa Transmídia: A Presenca de Sistemas de Narrativas Integradas e Complementares na Comunicacao e na Educacao. Quaestio, Sorocaba, SP, 13, 117-126.

[15] Sánchez, C. C. (2013). Narrativas Transmedia Nativas: Ventajas, Elementos de la Planificación de un Proyecto Audiovisual Transmedia y Estudio de Caso. Historia y Comunicación Social, 18, 561-574.

[16] Scolari, C. A. (2009). Transmedia storytelling: Implicit consumers, narrative worlds, and branding in contemporary media production.

[17] de Nooijer, S. (2019). Transmedia educational narrative design for craftsmanship (Doctoral dissertation, University of Applied Sciences).

[18] Osterwalder, A., \& Pigneur, Y. (2010). Business Model Generation. A Handbook for Visionaries, Game Changers, and Challengers. 
[19] CENTRO. (2017). Transmedia Storytelling Canvas. Retrieved January 3, 2020, from https://www3.centro.edu.mx

[20] Gambarato, R. R. (2019). A Design Approach to Transmedia Projects. In M. Freeman \& R. R. Gambarato (Eds.), The Routledge Companion to Transmedia Studies (1st ed., p. 569-). New York, NY: Routledge.

[21] Méndez, M. C., Somavilla, R. D., \& Sancho, A. (2017). Comunica2 como ejemplo de proyecto docente innovador. Mediamorfosis: Perspectivas sobre la innovación en periodismo, 73. 